\title{
Identification of Areas of Econophysical Models Application
}

\author{
Piotr Młodzianowski, Daniel Młodzianowski \\ Warsaw University of Technology, Warsaw, Poland
}

\begin{abstract}
The article presents results of reflections on practical applications of econophysical models in different fields and areas of the management support and answers the question: In what areas and scopes of the management process is usage of econophysical models already effective or very likely to be effective? It discusses the problem of gravity models and minority games used in economic and social sciences. Their applications in areas such as trade, transport, analysis of financial market fluctuations, or decision making are presented. An attempt is made to identify missing pieces in the area of broadly understood management, and possible directions for further research are suggested. The paper uses research methods such as desk research and literature review.
\end{abstract}

Keywords: gravity model, minority game, El Farol bar problem, econophysics, management, economics

\section{Introduction}

Econophysics is a scientific discipline from the frontier of economics, finance, mathematical finance, and statistical physics, dealing with complex economic systems. The basic idea of econophysics is that in statistical physics, economics and financial markets, individual elements of a complex system ${ }^{1}$ interact with each other resulting in noticeable changes to the whole system. Thanks to this observation many phenomena taking place in economy, as well as in financial markets, may be described using the laws and principles of physics. The laws of gravity, the first and second law of motion, and recently also statistical physics and quantum mechanics are the most commonly used in economics.

In the context of the above considerations, the aim of this article has been defined in the following way:

AG: Identification of the practical use of econophysical models in different fields and areas of the management support.

In order to achieve its main aim, the work focuses on the answer to the following research question:

RQ: In what areas and scopes of the management process is usage of econophysical models already effective or very likely to be effective?

Due to its limited volume, the article is limited to two econophysical models, i.e. a gravity model (referring to the universal gravity law), and a minority game model (referring to the laws of statistical physics). The results of the study are presented below.

Piotr Młodzianowski, master of science, Faculty of Management, Warsaw University of Technology, Warsaw, Poland.

Daniel Młodzianowski, master of science, Faculty of Management, Warsaw University of Technology, Warsaw, Poland.

Correspondence concerning this article should be addressed to Piotr Młodzianowski, Faculty of Management, Warsaw University of Technology, Narbutta 85, Warsaw 02-524, Poland.

${ }^{1}$ A complex system is a system made up of a large number of parts that interact with each other in a non-simple way. 


\section{Literature Review}

\section{Definition of Gravity Models}

The law of universal gravitation, also known as the law of gravity, states that each of the two material points is attracted to one another by the force directly proportional to the product of the masses of both points, and inversely proportional to the square of the distance between them. It can be expressed using the following formula:

$$
F=G \frac{m_{1} m_{2}}{d^{2}}
$$

where $m_{1} m_{2}$ are the masses of material points,

$d$ is the distance between these points,

$G$ is the proportionality factor,

$F$ is the gravity or force of gravity.

From the point of view of economic applications, the so-called gravity field is more important than gravity itself. It allows determining the quantity and direction of the gravitational force acting in the gravitational field on bodies that have mass. A quantity which characterizes the gravitational field is intensity of the gravitational field, expressed as:

$$
\gamma=\frac{M}{d^{2}}
$$

where $M$ is the mass of the source.

Economics also uses the concept of potential energy, described by the following formula:

$$
E_{p}=-G \frac{M m}{d}
$$

Attempts to use gravity models in economic and spatial research were undertaken at the beginning of the 20th century. However, the precursor of this study is J. Q. Stewart, a demographer who defined the concept of demographic power as an equivalent of potential energy, and the concept of demographic potential as an equivalent of the gravitational field potential. Centres such as cities, shopping malls, etc., became analogies of the material points, and the interaction became the economic equivalent of the word gravity. One of the earliest models was as follows:

$$
I_{i j}=G \frac{M_{i} M_{j}}{d_{i j}^{c}}
$$

where $I_{i j}$ means interaction between areas $i$ and $j$,

$M_{i} M_{j}$ are "masses" of two areas that can be measured by the population size,

$d_{i j}$ is the distance between the $i$ and $j$ areas,

$G$ is the equivalent of the gravitational constant, called calibration in economics,

$c$ denotes the distance exponent.

It should be stressed that the formula 4 is equivalent to 1 .

The following may serve as units (masses): country, economic region, province, city/town. The measure of mass, depending on the problem under consideration, is the number of households, the number of consumption spots, the number of warehouses and stores, the size of the sales and storage space, the number of beds in hospitals, the circulation of newspapers and magazines, the population size, etc. The distance, in turn, is 
measured in kilometres, however it may also be travel time or the product of price and travel time. Calibration refers to the model and is defined in such a way that the model under consideration should be well-matched to the empirical data (Heckman \& Leamer, 2001).

There are many issues related to gravity models. One of them, which is particularly noteworthy, is the model of trading mechanisms that was presented for the first time over half a century ago by the Dutch economist Jan Tinbergen (1962). Referring to the law of universal gravitation, he proposed a gravity model of trade between two countries, described by the following equation:

$$
O_{i j}=G \frac{G N P_{i} G N P_{j}}{d_{i j}}
$$

where: $O_{i j}$ is trade between countries $i$ and $j$,

$G N P_{i} G N P_{j}$ are the gross national product of the countries $i$ and $j$,

$d_{i j}$ is the geographical distance between countries $i$ and $j$,

$G$ is the equivalent of the gravitational constant, called calibration in economics.

According to the above equation, the size of bilateral trade between $O_{i j}$, countries $i$ and $j$ is positively correlated with the size of the economies of both countries, expressed by their gross national product $G N P_{i}$ and $G N P_{j}$, and negatively correlated with the distance between them $d_{i j}$ (Drzewoszewska, Pietrzak, \& Wilk, 2013).

When designing a gravity model that describes international relations, it is important to identify factors which influence the "attractiveness" of countries and determine the distance between trading partners (Gómez-Herrera, 2013). One of the factors determining trade volume is the size of the countries, which may be measured by: Gross Domestic Product (GDP), combination of Gross National Product (GNP), and population size (Linneman, 1966), as well as GDP per capita (Carrère, 2006). In gravity models of international trade, the geographic distance is a factor which weakens the attraction as it increases the time and costs of transport.

An attempt to identify trade factors using the above model was made in a work by Pietrzak and Lapińska (2014). Afterwards, evaluation was made of these model parameters which were considered to be significant determinants of trade levels between the countries of the European Union. They included: GDP, economic development measured by GDP per capita, as well as foreign direct investments. Also negative correlation of the geographical distance between the countries and the level of their mutual exchange was confirmed.

Models of commercial attractiveness and potential are an improvement of the gravity models. Among them, the Huff model (Huff, 1963) is of a particular attention. It is a probabilistic model used in spatial geomarketing analyses, which was developed by D. L. Huff (1962). According to L. D. Huff, the travel time and attractiveness of a shopping centre are factors which influence the consumer behaviour and may be used to forecast selection of the place for shopping. The Huff model formula is as follows:

$$
\operatorname{Prob}_{i j}=\frac{\frac{M_{j}}{T_{i j}}}{\sum_{j}^{n} \frac{M_{j}}{T_{i j}}}
$$

where:

$\operatorname{Prob}_{i j}$ is the probability that a single consumer residing in the $i$-th region will do shopping in the region $j$,

$M_{j}$ is the "mass" of the outlet (expressed, inter alia, by $\mathrm{m}^{2}$, the number of cash registers, the assortment range, etc.) used by the consumer $j$, 
$T_{i j}$ is the time it takes the consumer to move from the region $i$ to the outlet $j$.

In the economic practice, this model is quite often used. One of the examples has been presented in the work (Pan-Jin, Wanki, Won-Ki, \& Myoung-Kil, 2011), where the Huff model was used to forecast store sales. The authors modified the model to include variables such as costs of advertising and promotion or brand recognisability. The results of a survey carried out in four retail stores used as a sample proved to be satisfactory, with the forecast error rate reaching the level of $5 \%$. However, it was noted that they should not be generalized because of too small research sample.

Gravity is not the only physics principle that is successfully used in economics and social sciences. Also statistical physics and the minority game model based on it are also worth mentioning. They will be discussed in the next subsection.

\section{Definition of Minority Games}

In the minority game model (MG), market participants, who are very numerous (for instance continuum), buy and sell securities. The trade is based on the analysis of the stock price fluctuations and information reaching the market. If majority of the market participants intend to acquire securities, then it is worth to sell them and vice versa. As a rule, players in the minority group win the game. All market participants make decisions using certain "information patterns". Therefore, there are three types of players in the minority game:

- players producing information noise and making accidental decisions;

- producers behaving in a deterministic manner;

- profiteers.

Actions taken by these three groups are cumulative and lead to qualitative changes in the whole system, as is the case in macroscopic physical systems, where macro-electromagnetic interactions are observed. The MG, when referred to financial markets, provides a precise illustration of the allocation of capital and financial instruments by means of statistical physics rules. Statistical physics deals with macroscopic physical systems consisting of atoms and particles, and examines their behaviour. These may be: solids, liquids, gases, as well as living organisms of various forms and compositions. Such systems seek a state of equilibrium which does not tend to change over time, except for random fluctuations, with some states of the macroscopic system being more probable than others. It should be noted that interactions between market participants are modelled on physical interactions and are the subject of econophysics (Drabik, 2012).

The research on minority play was initiated by W. Brian Arthur, who defined so-called El Farol bar problem in his work (Arthur, 1994). It is made up of $\mathrm{N}$ participants referred to as investors or market participants. The minority game may be described as follows:

1. It is assumed that the game in the financial market is a non-zero game with the $\mathrm{N}$ number of investors $(\mathrm{N} \rightarrow \infty)$.

2. At any $t(\mathrm{t}=1,2, \ldots)$ time of the game, every market participant may, though does not have to, make one of the two decisions: either buy or sell, which is expressed as $a_{i}(t)=+1$ or $a_{i}(t)=-1$.

3. The payment (profit) for the $i$-th investor is determined by the following equation:

$$
g_{i}(t)=-a_{i}(t) A(t)
$$

where 


$$
A(t)=\sum_{j=1}^{N} a_{j}(t)
$$

The value $A(t)$ means the difference between the number of investors who made a decision to sell and the number of investors who made a decision to buy stocks in time $t$. If $A(t)>0$, investors who made a decision $a_{i}(t)=-1$ win, and those who made a decision $a_{i}(t)=+1$ lose.

4. The strategy $s_{i}(t)$ of investor $i$ in time $t$ is evaluated on the basis of information $\{1, \ldots \mu, \ldots \mathrm{P}\}$, obtained by the market participant in the course of the game. It is defined as follows: $s_{i}(t):\{1, \ldots \mu, \ldots \mathrm{P}\} \rightarrow$ $\{-1 ;+1\}$. In the case in question, the information includes both the history of the game and the sequence of past decisions made by both minority and majority investors, as well as certain information obtained from the outside.

5. Given the information received and the "adaptability" of individual market participants, the profit of $i-t h$ investor may be expressed in the following way:

$$
g_{i}(t)=-a_{i}(t)_{s_{i}(t), i}^{\mu(t)} A^{\mu(t)}(t)
$$

where

$$
A^{\mu(t)}(t)=\sum_{j=1}^{N} a_{\mathrm{s}_{\mathrm{j}}(\mathrm{t}) \mathrm{j}}^{\mu(\mathrm{t})}(t)
$$

where

$$
a_{i}(t) \rightarrow a_{i}(t)_{S_{i}(t), i}^{\mu(t)} \text { i } \quad A(t) \rightarrow A^{\mu(t)}(t)
$$

6. The goal of every market participant is to maximize profit $g_{i}(t)(i=1, \ldots, N)$ at any stage of the game $t$.

The presented issue may be solved in a number of ways. For example, Challet, Marsili, and Zhang (2000, pp. 284-315) and Mosetti, Challet, and Zhang (2005, pp. 529-542), by modelling financial markets using minority game, focus on studying functions $A(t)$. They note that variance $\sigma^{2}(t)=\langle A(t)\rangle$ is a measure of the distribution of funds on the market, and the equation: $\alpha=\frac{\mathrm{P}}{\mathrm{N}}$ of the information level. When $\alpha>1$, the market has too much information, and investors made random decisions. When $\alpha \rightarrow 1$, more investors join the game, and information flowing to the market is used more effectively. If $\alpha$ reaches its minimum:

$$
\left(\alpha=\frac{7}{20}\right)
$$

the behaviour of market participants may be compared to the course of critical phenomena in statistical physics (Drabik \& Młodzianowski, 2016).

The probability of a particular decision made by each investor is determined in the following way:

$$
\operatorname{Prob}\left\{a_{i}(t)= \pm 1\right\}=\frac{e^{ \pm g_{i}(t)}}{e^{g_{i}(t)}+e^{-g_{i}(t)}}
$$

In the minority game model, it is not possible to "precisely" determine the stock price at the time $(t) i$ $(t+1)$. It is assumed that the change in the price of stocks is shaped by the number of buy and sell orders. If investors wishing to sell stocks have majority, the stock price drops. The price will increase if the buyers form 
the majority. In the minority game, a difference between the number of investors who made a decision to sell stocks and the number of investors who made a decision to buy them in time $t$ is calculated using the following formula (13):

$$
A(t)=\sum_{j=1}^{N} a_{j}(t)
$$

The value of the stock price change depends on the sensitivity to the changes in the number of buy and sell orders. This is referred to as market depth. Therefore, analysis of rates of return in minority games is reduced to the assumption of linear dependence:

$$
r_{(t)}=\log \left(p(t+1)-\log (p(t))=\frac{A(t)}{\lambda}\right.
$$

where $\lambda$ is a parameter measuring sensitivity of the price to the changes in the number of buy and sell orders.

The presented model of minority games is successfully used in the financial markets. The research carried out by K. Wawrzyniak (2011), predicting changes in the stock prices exerting the biggest impact on the main index of the Warsaw Stock Exchange, should also be mentioned. The success rate of the price change direction forecasts ranged from $53 \%$ to $70 \%$ depending on the adopted parameters of the model. In turn, Challet, Marsili, and Zhang (2001) used the MG as a simple player-based model of financial markets which is able to map the so-called stylized facts, such as: atypical distribution of the rate of return or volatility grouping.

Minority games have also been used in the road traffic modelling. Research in this area was carried out, inter alia, by Kuen (2002), Chmura (2004), and Galib and Moser (2011). The said works examined relationships between the size of the group making minority decisions and the benefits derived by that group in terms of quicker reaching of the destination point. They analysed what information was most useful in taking decisions on the route selection and possibilities of interaction between the closest game participants, consisting in the imitation of the fastest moving game participant. It turned out that moderate imitation is conducive to reducing travel time between the points. The most useful information when making decisions of a route was: the total travel time and the current average speed of the vehicle.

Another model inspired by the minority game, used in biology and epidemiology, and relating to the decision-making issues, was proposed by Vardavas, Breban, and Blower (2007). It covers N number of persons who do not communicate with each other and who make decisions about vaccinations. Each year, these persons individually decide whether to vaccinate against influenza or not, using an effective vaccine with no side effects. Persons in the model are characterized by two biological characteristics (adaptability and memory) which they use when taking decisions on vaccination. The model attempts to determine the impact of individual vaccinations on decisions to vaccinate against influenza epidemiology, as well as the impact of influenza epidemiology on vaccination decisions at the individual level. It was analysed whether vaccination programs without any incentives are able to cover population at the level which prevents the occurrence of an influenza epidemic. It was also assessed how motivational systems such as, inter alia, free vaccinations, affect the vaccination level. The potential impact of the program of vaccination of entire families on the epidemic frequency was also analysed. It turned out that if the decision to vaccinate the entire family is taken by the head of the family, the incidence of serious epidemics increases. This is due to the fact that the severity and incidence of epidemics are a function of the number of persons who make decisions about vaccination on their own. Giving the head of the family the right to decide about vaccination reduces the number of independent 
decision-makers, which results in the fact that non-vaccinated persons more frequently express their major hesitations regarding vaccination. It was found that the program of family vaccinations had increased the frequency of serious epidemics, and vaccination was more often used by persons displaying long-term commitment to the program who had not gone down with influenza.

Relationships between the minority game and the auction market were analysed by Lustosa and Cajueiro (2010). In their work, they introduced a modified MG model in which the only game participants who had information about whether they were in a minority or majority group were those who participated in the auction. Subject to varying probabilities, other participants might receive this information from other players who actually participated in it, or from the media. Authors prove that if access to information is limited, the game may not revolve around the optimal division between minority and majority groups. There is a possibility of arbitration, and the greatest benefits are derived by the player having the information. On the other hand, there is a critical point above which the number of players present at the auction is able to convey the information to the absent persons. The authors noted that the dynamics of the game reflected in a good manner the dynamics of the goods auctions, in particular vehicles on the Brazilian market.

\section{Research Results}

\section{Possibilities of Using Econophysical Models in Management}

Table 1 was prepared in the search for areas of use of the econophysical models and answered the research question. It shows areas of application of the discussed models along with the missing pieces where the use of models is very limited or does not exist. It also contains references to sources of the research works which represent the specified areas of application.

Table 1

Areas of Application of Econophysical Models

\begin{tabular}{|c|c|c|}
\hline $\begin{array}{l}\text { Model type } \\
\text { Area of applications }\end{array}$ & Minority games & Gravity model \\
\hline Auctions & $\begin{array}{l}\text { Lustosa \& Cajueiro, } 2010 . \\
\text { Zeng, Davis, \& Abbott, } 2007 .\end{array}$ & \\
\hline Capital market & $\begin{array}{l}\text { Bonnet \& Abbott, } 2010 . \\
\text { Challet, Marsili, \& Zhang, } 2013 . \\
\text { Krause, 2009. } \\
\text { Wawrzyniak, 2011. } \\
\text { Wawrzyniak \& Wiślicki, } 2011 .\end{array}$ & $\begin{array}{l}\text { Ferwerda, Kattenberg, Chang, Unger, Groot, \& Bikker, } \\
2013 .\end{array}$ \\
\hline Transport & $\begin{array}{l}\text { Galib \& Moser, } 2011 . \\
\text { Chmura \& Pitz, } 2006 . \\
\text { Chmura, 2004. }\end{array}$ & $\begin{array}{l}\text { De Jong, Vierth, Tavasszy, \& Ben-Akiva, } 2013 . \\
\text { Khadaroo \& Seetanah, } 2008 .\end{array}$ \\
\hline International trade & & $\begin{array}{l}\text { Pietrzak \& Łapińska, } 2014 . \\
\text { Baltagi, Egger, \& Pfaffermayr, } 2014 . \\
\text { Novy, 2013. }\end{array}$ \\
\hline Local trade & & $\begin{array}{l}\text { Pan-Jin, Wanki, Won-Ki, \& Myoung-Kil, } 2011 . \\
\text { Migdał-Najman \& Mudza, } 2009 . \\
\text { Wiśniewski, } 2016 .\end{array}$ \\
\hline Biology (decision-making) & Vardavas, Breban, \& Blower, 2007. & \\
\hline Demography & & Bunea, 2012. \\
\hline Management & Huang, Cai, Xu, \& Yu, 2017. & \\
\hline
\end{tabular}

Source: Own work. 


\section{Findings and Discussion}

Gravity models and MG are used in many areas of application as shown in Table 1. However, the possibility of their implementation is closely linked to the laws of physics they derive from. Apart from the above-mentioned applications, gravity models may be used in a large number of other areas. One of them is education. When deciding to launch a new field of study, higher schools should estimate the potential number of candidates interested in this field. The Huff model might be used for this purpose. As in the case of forecasting the sales volume of newly opened stores, factors such as prestige, competition proximity, size of the city, and potential number of candidates should be taken into account. A similar problem which addresses the issue of student migration was presented in the work by Cullinan and Duggan (2016). The gravity model is quite often exploited in literature. It is used to determine location of the planned airports, railway stations, or interchange stops (Khosravi \& Akbari, 2017). There are a large number of application possibilities. A diagram showing intensity of the usage of gravity models in selected management aspects is shown below.

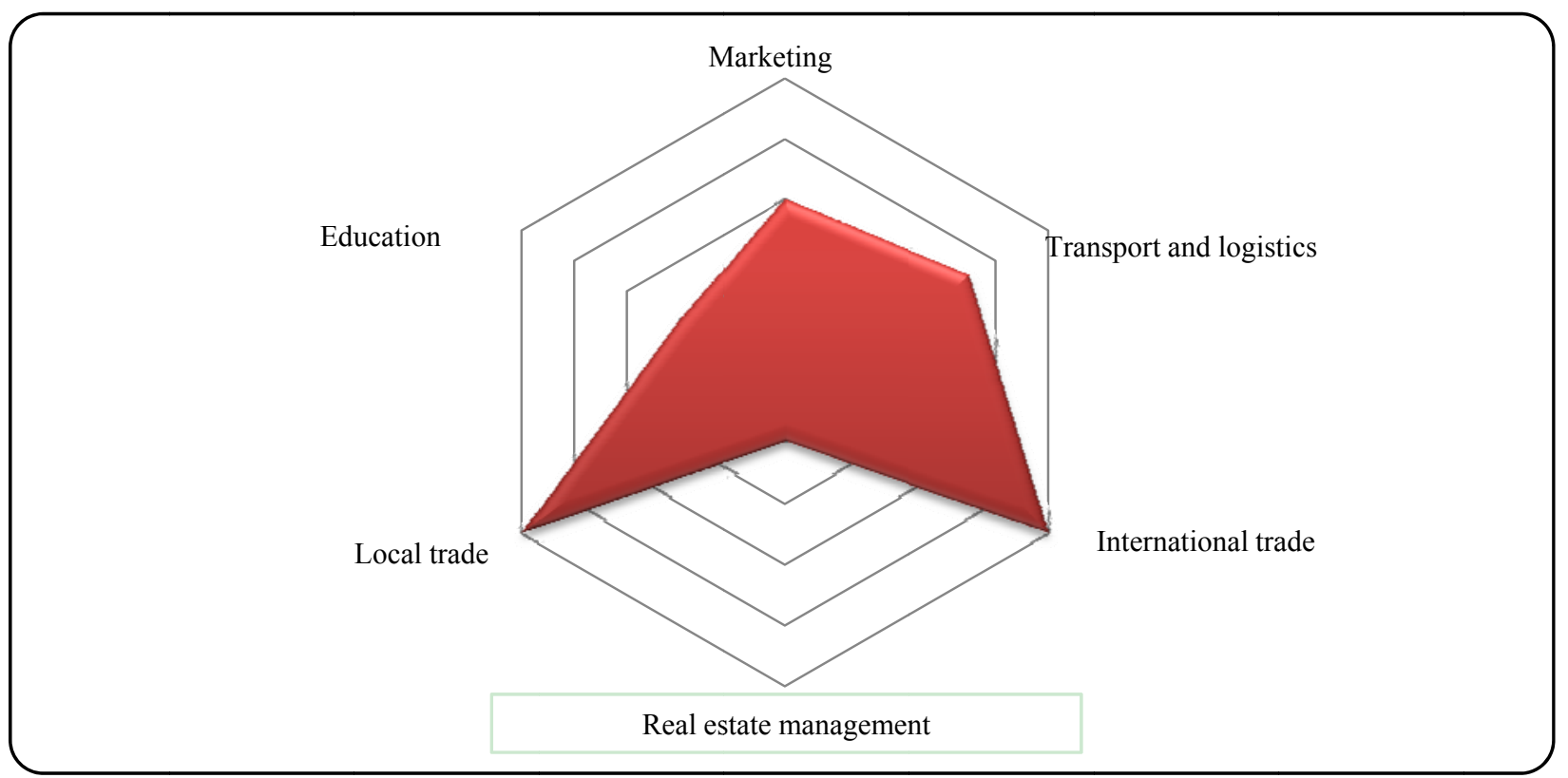

Figure 1. Gravity model application areas. Source: Own work.

Despite popularity of using the gravity model in estimating trade exchange at international level and in identification of retail locations in the local market, a recurring problem should be noted. The model only allows an approximate determination of estimated values and additionally specifying the calibration constant ${ }^{2}$ which allows referring the theoretical model to economic realities. Its determination requires a lot of research and experiments, which directly reduce popularity of the gravity model in areas such as marketing, education, or real estate management. Currently, advanced computer techniques based on artificial intelligence (for instance neural networks) and fuzzy logic (increasing tolerance to uncertainty and incompleteness of analytical data) are more and more often used to forecast and simulate economic phenomena along with development of analytical tools.

\footnotetext{
${ }^{2}$ Calibration - an activity consisting in the selection of model parameters in a way that allows to achieve simulation results similar to the set of data determining behaviour of a real object.
} 
In the case of MG, further research should analyse behaviours of the game participants depending on the number of available strategies. It turns out that when the number of players compared with the number of strategies reaches a critical value (amounting to in the case of MG), herding behaviour may occur. This analogy may be used, for instance, in the studies of crowd behaviours during mass events. Simply replace the number of strategies with the number of evacuation locations in order to determine what number of evacuations locations allows safe evacuation in case of emergency.

It has already been mentioned, minority games involve many players, who are often referred to as agents, making decisions based on the available information. An analogy should be noticed here to artificial intelligence (AI) methods, in which agents are also used. In both the MG and the AI, the task of agents is to solve dispersed or computationally complex issues (Bond \& Gasser, 2014). Therefore, there is still a large room for MG applications, especially in those areas where population behaviours are analysed.

Management in its broad meaning is obviously an area of MG applications that is hard to exploit, yet one should pay attention to the analogy between forecasting investor behaviours, which often uses MG, and risk management in the financial market. The ability to forecast investor behaviours may significantly reduce the level of risk associated with the decisions made. Minority games may also be adapted for production and resource management. Thanks to the built-in system of self-educating players who make decisions based on past events and available resources, allocation of the resources and their optimized usage within the undertaking may be simulated (Zhang, Wu, Huang, \& Yu, 2012).

\section{Conclusions}

Presentation of the physical models used in economics and proposing new possibilities for their use in the management context allowed achieving the defined goal and answering the formulated research questions. The basic conclusion drawn from the work is that there is a broad room for using physical methods in various fields of economic, managerial, and financial applications. They can be used to examine, inter alia, demographic changes, sales forecasts, trade volumes between countries, or behaviours during epidemics. It should be concluded that physical methods also apply to financial markets. There are many models of financial markets, inter alia: minority games models in which analogies to electromagnetic interactions are successfully used to reflect behaviours of investors. However, despite a large number of applications of the above models and the room for further research, it seems that they are increasingly displaced by models based on neural networks and other artificial intelligence methods. In the authors' opinion, they are a solid alternative and complement them as they are characterized by lower degree of computational complexity, which allows avoiding the so-called "black box" effect we face in the case of neural networks.

\section{References}

Arthur, W. B. (1994). Inductive reasoning, bounded rationality, and the bar problem. American Economic Review, 84. Baltagi, B. H., Egger P. H., \& Pfaffermayr, M. (2014). Panel data gravity models of international trade. In B. H. Baltagi (Ed.), The Oxford handbook of panel data econometrics (pp. 608-641). Oxford: Oxford University Press.

Bonnet, F. D. R., \& Abbott D. (2010). Can a minority game follow real market dynamics? Fluctuation and Noise Letters, 1, 107-128. Bond, A. H., \& Gasser, L. (2014). Readings in distributed artificial intelligence. Morgan Kaufmann.

Bunea, D. (2012). Modern gravity models of internal migration. The case of Romania. Theoretical and Applied Economics Volume XIX, 4(569).

Carrère, C. (2006). Revisiting the effects of regional trade agreements on trade flows with proper specification of the gravity model. European Economic Review, 50(2). 
Challet, D., Marsili, M., \& Zhang, Y. C. (2000). Modeling market mechanism with minority. Physica A, 276.

Challet, D., Marsili, M., \& Zhang, Y. C. (2001). Stylized facts of financial markets and market crashes in minority games. Physica A: Statistical Mechanics and Its Applications, 294(3), 514-524.

Challet, D., Marsili, M., \& Zhang, Y. C. (2013). Minority games: Interacting agents in financial markets. OUP Catalogue.

Chmura, T. (2004). Minority game: Experiments and simulations of traffic scenarios. Bonn Econ. Discussion Papers, 23.

Chmura, T., \& Pitz, T. (2006). Successful strategies in repeated minority games. Physica A: Statistical Mechanics and Its Applications, 363(2), 477-480.

Cullinan, J., \& Duggan, J. (2016). A school-level gravity model of student migration flows to higher education institutions. Spatial Economic Analysis, 11.

De Jong, G., Vierth, I., Tavasszy, L., \& Ben-Akiva, M. (2013). Recent developments in national and international freight transport models within Europe. Transportation, February, 40(2).

Drabik, E., \& Młodzianowski, P. (2016). Some remarks about financial market modelling using a minority game approach. Economics, 4(5), 216-223.

Drabik, E. (2012). Wybrane modele mechanizmów rynkowych Oparte na prawach fizyki statystycznej i mechaniki kwantowej. Optimum Studia Ekonomiczne, 2(56).

Drzewoszewska, N., Pietrzak, M. B., \& Wilk, J. (2013). Grawitacyjny model przepływów handlowych między krajami Unii Europejskiej w dobie globalizacji. Roczniki Kolegium Analiz Ekonomicznych.

Ferwerda, J., Kattenberg, M., Chang, H. H., Unger, B., Groot, L., \& Bikker, J. A. (2013). Gravity models of trade-based money laundering. Applied Economics, 45(22), 3170-3182.

Galib, S. M., \& Moser, I. (2011). Road traffic optimisation using an evolutionary game. Proceedings of the 13th annual Conference Companion on Genetic and Evolutionary Computation.

Gómez-Herrera, E. (2013). Comparing alternative methods to estimate gravity models of bilateral trade. Empirical Economics, 44(3).

Heckman, J. J., \& Leamer E. (2001). Handbook of econometrics value 5. North Holland.

Huang, H., Cai, Y., Xu, H., \& Yu, H. (2017). A multiagent minority-game-based demand-response management of smart buildings toward peak load reduction. IEEE Transactions on Computer-Aided Design of Integrated Circuits and Systems, 36(4), 573-585.

Huff, D. L. (1963). A probability analysis of shopping centre trade areas. Land Economics, 53.

Khadaroo, J., \& Seetanah, B. (2008). The role of transport infrastructure in international tourism development: A gravity model approach. Tourism Management, 29(5), 831-840.

Khosravi, S., \& Akbari Jokar, M. R. (2017). Facility and hub location model based on gravity rule. Computers \& Industrial Engineering, 109.

Krause, A. (2009). Evaluating the performance of adapting trading strategies with different memory lengths. In Proceeding of IDEAL 2009, 711-718.

Kuen, L. (2002). Studies on the minority game and traffic flow models. Chinese University of Hong Kong.

Linneman, H. (1966). An econometric study of international trade flows. North-Holland.

Lustosa, B. C., \& Cajueiro, D. O. (2010). Constrained information minority game: How was the night at El Farol? Physica A: Statistical Mechanics and Its Applications, 389(6), 1230-1238.

Migdał-Najman, K., \& Mudza, A. (2009). Zastosowanie modelu grawitacji względnej Huffa w analizie rynku wielkopowierzchniowych placówek handlowych. Marketing i Rynek, (3), 27-34.

Mosetti, G., Challet, D., \& Zhang, Y. C. (2005). Heterogenous time scales in minority game. Physica A: Statistical Mechanics and Its Applications.

Novy, D. (2013). Gravity redux: Measuring international trade costs with panel data. Economic Inquiry, 51(1), 101-121.

Pan-Jin, K., Wanki, K., Won-Ki, C., \& Myoung-Kil, Y. (2011). Using new Huff model for predicting potential retail market in South Korea. African Journal of Business Management, 5(5).

Pietrzak, M. B., \& Łapińska J. (2014). Zastosowanie modelu grawitacji do identyfikacji czynników determinujących przepływy handlowe w Unii Europejskiej. Przeglad Statystyczny, 61(1), 65-77.

Vardavas, R., Breban, R., \& Blower, S. (2007). Can influenza epidemics be prevented by voluntary vaccination? PLoS Comput Biol., 85.

Wawrzyniak, K. (2011). On phenomenology, dynamics and some applications of the minority game (Ph.D. dissertation, Polish Academy of Science) (in Poland). 
Wawrzyniak, K., \& Wiślicki, W. (2011). Minority games as a predictor of future signal changes. In Submitted to European Conference on Complex Systems ECCS 2011.

Wiśniewski, S. (2016). Dostępność mieszkańców województwa łódzkiego do sklepów wielkopowierzchniowych. Acta Universitatis Lodziensis. Folia Geographica Socio-Oeconomica.

Zeng, Q., Davis, B. R., \& Abbott D. (2007). Reverse auction: The lowest unique positive integer game. Fluctuation and Noise Letters, 7(04), L439-L447.

Zhang, C., Wu, W., Huang, H., \& Yu, H. (2012). Fair energy resource allocation by minority game algorithm for smart buildings. In Design, Automation \& Test in Europe Conference \& Exhibition (DATE), 63-68. 